\title{
3
}

\section{A ONTOLOGIZAÇÃO DA LÓGICA EM HEGEL COMO CRÍTICA À CRÍTICA KANTIANA À ONTOLOGIA CLÁSSICA}

Regenaldo Rodrigues da Costa*

SINTESE - Durante aproximadamente vinte séculos o que se entendia predominantemente como ciência era a ontologia clássica (Metafísica clássica), entretanto, a partir da modernidade ela começou a perder o status de cientificidade e foi a filosofia critica de Kant que de forma radical apontou para a sua impossibilidade enquanto ciência. Hegel, porém, acha que a ciência só é verdadeiramente efetiva enquanto ontologia, de modo que ele toma como tarefa de sua filosofia o resgate da ontologia enquanto ciência. Neste horizonte, Hegel através da ontologização da lógica se propõe a resgatar a ontologia enquanto ciência, porém esta é uma nova concepção de ontologia e se apresenta como critica em relação à ontologia clássica e a crítica kantiana à ontologia clássica.
ABSTRACT - During around twenty centuries, science and classic ontology were considered words with the same meaning, although, with the modernity dawning, the classic metaphysic missed its scientific status and, in this context, Kant showed the impossibility of the classic ontology to be accepted as a science. Hegel had a different comprehension, he defended that the science is just as such when it is made out ontology, for that reason, Hegel fixed as his task to demonstrate the scientifically of the ontology. $\mathrm{So}$, in the act of to conceive the logic as ontology, Hegel tented to rescue the ontology as science and created a new conception about ontology that manifest, at the same time, a critic against the classic ontology and other towards the critic that Kant did against the classic ontology.

Neste trabalho pretendemos apresentar uma pequena introdução à noção da ontologização da lógica na compreensão do filósofo alemão Hegel. Esta ontologização da lógica em Hegel é uma crítica à crítica kantiana à ontologia que lhe precedeu. Neste horizonte, tematizaremos a lógica hegeliana como um resgate da ontologia, enquanto ciência, destronada do reino da ciência por Kant e, ao mesmo tempo, a apresentaremos como uma nova concepção de ontologia, a qual pressupõe a crítica à ontologia clássica e a crítica à crítica kantiana da ontologia clássica, sendo, deste modo, uma meta-crítica.

No desenvolvimento deste trabalho apresentaremos três temáticas principais: na primeira, apresentaremos uma introdução à concepção de método em Hegel;

* Mestrando em Filosofia da PUCRS e professor da Universidade Estadual do Ceará, UECE.

\begin{tabular}{|l|l|l|l|l|l|}
\hline VERITAS & Porto Alegre & v. 42 & $\mathrm{n}^{\circ} 4$ & Dezembro 1997 & p. $845-868$ \\
\hline
\end{tabular}


na segunda, uma introdução à concepção da lógica ontologizada em Hegel; e finalmente, na terceira, uma introdução à ontologia hegeliana como a proposta de uma nova ontologia, a qual se apresenta como crítica em relação à ontologia clássica e à crítica kantiana à ontologia clássica.

Consideramos esta leitura um pequeníssimo degrau na compreensão desta monumental produção do espírito humano que é a lógica-ontológica hegeliana. Sem maiores pretensões, fazemos votos de que tenhamos sido fiéis ao espírito da filosofia de Hegel.

\section{1 - Introdução à concepção de método em Hegel}

Hegel pretende que a filosofia assuma a forma da ciência e isto significa que a filosofia não pode se contentar com um saber das aparências, ou seja, ela tem que ser um saber efetivo e, deste modo, dar conta do real. Assim sendo, a concepção hegeliana de método, lógica, ciência, etc., tem esta meta como pressuposto e isto é bastante claro na seguinte afirmação de Hegel: "Trabalhar no sentido de que a filosofia se aproxime da forma da ciência - e da meta na qual ela possa deixar seu nome de amor ao saber e ser saber efetivo - eis o propósito que me atribui".'

Porém, para Hegel, a filosofia diferentemente das outra ciências, não pode pressupor os seus objetos como imediatamente dados pela representação e nem pressupor como admitido o método do conhecer. Assim então, a filosofia pode apenas pressupor um trato com os seus objetos e isto porque "[...] a consciência, na ordem do tempo, forma primeiro representações do que conceitos dos mesmos [...]"..2.

Ora, só através de representações se progride para o conhecimento e para o conceito, entretanto, "[...] pelo fato de se ter representações, nem por isso se conhece o seu significado para o pensar, isto é, não se conhecem ainda os seus pensamentos e conceitos" e ademais, para Hegel, as representações são consideradas como metáforas dos conceitos, de modo que "[...] a filosofia, no lugar das representações, põe pensamentos, categorias e, mais precisamente, conceitos". .

A filosofia reivindica o pensar como forma de sua ocupação. Ora, para Hegel, o verdadeiro conteúdo de nossa consciência se apresenta em sua verdadeira luz só quando traduzido para a forma do pensamento e do conceito e isto implica, portanto, que o conteúdo da filosofia é a realidade efetiva, ou seja, o que se produziu no domínio do espíito (o que se tornou mundo interno e externo da consciência).

Para Hegel, o espírito nunca está em repouso, mas é concebido sempre em movimento. Deve-se dizer, então, do absoluto, que o que ele é na verdade se expressa apenas no fim, pois ele é o resultado e contém todo o processo. Ora, o absoluto, enquanto é o verdadeiro, "[...] é o devir de si mesmo, o circulo que pressupõe seu fim como seu alvo, tem seu fim como princípio e é efetivo somente por meio de sua realização e de seu fim". ${ }^{6}$ Nesta perspectiva, a ciência que, para He-

\footnotetext{
Hegel, G. W. F. Fenomenologia do Espírito. Hegel, os pensadores, p. 7.

Hegel, G. W. F. Enciclopédia das Ciências Filosóficas, p. 69.

Hegel, G. W. F. Op. cit., p. 71.

Hegel, G. W. F. Op. cit., p. 71.

Hegel, G. W. F. Op. cit., p. 13.
} 
gel, é a coroa de um mundo do espirito, não está perfeita no seu começo, pois o verdadeiro é o todo, todo este que atinge a completude por meio de seu desenvolvimento.

Neste horizonte, Hegel considera o resultado idêntico com o começo, pois o começo é o fim e o fim atualizado ou o efetivo existente é o movimento e devir desenvolvido, entretanto, ele considera o permanecer no começo, no imediato, resultado da ignorância da mediação, que é uma atualização positiva do começo e ao mesmo tempo, um comportar-se negativo para com ele.

Podemos dizer, então, com Hegel, que somente o sujeito é a substância verdadeira, viva, ou seja, ele é o ser ou a imediatidade que não tem fora de si a mediação, mas é a própria mediação. Pois bem, para Hegel, "a substância vivente é também o ser que na verdade é sujeito ou, o que dá no mesmo, é verdadeiramente efetivo somente na medida em que é o movimento de pôr-se-a-si-mesma, que é a mediação consigo mesma do tornar-se ser outra" e mais, "[...] a coisa não se consuma no seu fim, mas na sua atuação e o todo efetivo não é o resultado, a não ser juntamente com seu devir".

Para Hegel, o fim da ciência é o sujeito, de modo que a tarefa da ciência é apreender o verdadeiro como sujeito. Segundo seu modo de ver, que somente a exposição do sistema deve justificar, "[...] tudo depende de apreender e exprimir o verdadeiro não como substância, mas, exatamente na mesma medida, como sujeito"' e mais, o espirito que se sabe assim desenvolvido como espírito é a ciência.

Podemos dizer, portanto, que "o puro reconhecer-se a si mesmo no absoluto ser outro, este éter como tal é o fundamento e o terreno da ciência ou o saber em geral",' entretanto, convém explicitar que este reconhecer-se do espírito, que é a ciência, só se expressa plenamente através do movimento de seu devir e o princípio do sistema é, na realidade, apenas seu começo.

Ora, quando se exprime o absoluto como espírito, está expresso que a substância é essencialmente sujeito e que deve, portanto, reconhecer-se enquanto verdadeiro como sistema; desta forma, o espírito em seu desenvolvimento se sabe a si mesmo como o seu outro que retorna a si, que se torna em si e para si no elemento da ciência, o conceito, pois no conceito a verdade pode receber a estrutura da ciência ou do sistema.

Nesta perspectiva, o que parece acontecer fora da substância é o seu próprio operar, onde ela se mostra sujeito, e quando a substância tiver mostrado plenamente esta sua natureza o existir do espíito será igual à sua essência. Assim, portanto, quando o espírito for para si assim como é, a separação do saber e da verdade está superada, o ser está absolutamente imediatizado, ou seja, tem a forma de si ou é conceito, o que é principio e meta da ciência; Ora, é neste momento que termina a fenomenologia do espírito e nela o espírito preparou para si o elemento do saber.

Hegel, G. W. F. Op. cit., p. 13.

Hegel, G. W. F. Op. cit., p. 13.

Hegel, G. W. F. Op. cit., p. 12.

Hegel, G. W. F. Op. cit., p. 16. 
Pois bem, no elemento do saber não há mais a separação entre ser e saber, pensamento e realidade, sujeito e objeto, pois o espírito sabe a si mesmo como objeto e no desenvolvimento do todo ou o conceito a sua diversidade é apenas de conteúdo. Ora, para Hegel, "no elemento do saber os momentos do espírito se expandem [...] na forma da simplicidade, que sabe seu objeto como a si mesma"10 $\mathrm{e}$ isto é, também, o lógico, pois "o movimento dos momentos que se organiza como um todo no elemento do saber é a lógica ou a filosofia especulativa “.

Ora, na lógica começa o desenvolvimento do método da ciência, que outra coisa não é do que a estrutura do todo apresentada em suas puras essencialidades, onde não há separação entre ser e saber. Há apenas um desenvolvimento desta identidade de saber e ser, na medida em que ela se mediatiza, se reflete, e mais, a sua exposição propriamente dita é a ciência da lógica no seu todo, pois "[...] a ciência exige a riqueza que flui de si mesma e a diferença das figuras que a si mesmo se determina"."

Nesta perspectiva, Hegel coloca no automovimento do conceito, que é um movimento lógico-ontológico, a própria razão de existir da ciência. Ora, isto significa, que no trabalho da ciência tudo consiste em tomar sobre si próprio o esforço do conceito, pois os pensamentos verdadeiros e a intelecção científica somente podem alcançar seus resultados no trabalho do conceito; Portanto, "renunciar à própria incursão no ritmo imanente do conceito, não intervir nele arbitrariamente por meio de uma sabedoria adquirida de qualquer maneira que seja, é uma forma de abstenção que pertence também à atenção ao conceito".

Podemos dizer, então, que para Hegel todo conteúdo é uma reflexão sobre si mesmo e que o saber não pode refletir em si fora dele, pois o que leva a ciência a organizar-se é o próprio movimento do conteúdo, que é um movimento dialético. Desta forma, não podemos pressupor um método anterior e exterior ao movimento deste conteúdo, pois na filosofia especulativa o método é imanente ao conteúdo e o conteúdo é sujeito.

Podemos concluir, portanto, que para Hegel o método é o trabalho do conceito e sua exposição é a ciência da lógica, e mais, ele é a razão de existir a ciência, de modo que

\footnotetext{
"Somente este trabalho pode produzir a universalidade do saber. Tal universalidade não é nem a indeterminação e indigência do senso comum, mas o conhecimento cultivado e acabado, nem a universalidade extraordinária da disposição da razão que se corrompe com a preguiça e a presunção do gênio, mas a verdade que cresce até alcançar sua forma ingênita, capaz de se tornar a propriedade de toda razão consciente de si"12
}

\footnotetext{
Hegel, G. W. F. Op. cit., p. 22.

Hegel, G. W. F. Op. cit., p. 22.

Hegel, G. W. F. Os pensadores. p. 38.
} 


\section{2 - Introdução à concepção da lógica ontologizada em Hegel}

\section{1 - A necessidade hegeliana de repensar a lógica}

Para Hegel, a completa transformação que se produziu na maneira filosófica de pensar, até o final do século XVIII, teve escassa influência sobre a lógica, o que não aconteceu com a metafisica, pois "o que antes de dito periodo se chamava metafísica, foi, por assim dizer, totalmente arrancado de raiz e desapareceu do conjunto das ciências"."

Nesta perspectiva, perdeu-se o interesse pelo conteúdo e pela forma da metafísica, entretanto, para Hegel, foi a filosofia kantiana que justificou, do ponto de vista científico, a renúncia ao pensamento especulativo, ao afirmar que o intelecto não pode ir além da experiência.

Quanto à lógica, näo se imaginava melhor sorte para ela do que para a metafísica. Porém, a lógica não se saiu tão mal como a metafísica e apesar de ter perdido o conceito de que com ela se poderia aprender a pensar, conservou um lugar entre as ciências; entretanto, "o novo espírito científico surgido na ciência não menos que na realidade, não transluz, todavia, nela"."

Hegel considerava que não se havia tratado adequadamente a ciência da lógica, pois "[...] a ciência da lógica que constitui a própria metafísica ou filosofia especulativa pura, foi até agora muito descuidada". . Ora, para ele, se fazia necessário levar em conta a necessidade de começar de novo desde o começo esta ciência, o que não foi realizado em trabalhos anteriores ao seu.

Neste sentido, era fundamental um novo procedimento científico. Ora, para ele, "só a natureza do conteúdo pode ser a que se move no conhecer científico, posto que é ao mesmo tempo a própria reflexão do conteúdo, a que funda e cria a sua própria determinação"," por conseguinte, "a filosofia se tem que ser ciência, não pode [...] tomar emprestado para este fim seus métodos de outra ciência subordinada, como seria a matemática"."

A filosofia, portanto, só pode ser uma ciência objetiva e demonstrativa através de caminhos que ela constrói por si mesma, pois o movimento espiritual que só a filosofia pode realizar representa, ao mesmo tempo, o desenvolvimento imanente do conceito e o método absoluto do conhecimento.

Faz-se necessánio, então, superar as determinações fixas do intelecto, pois "o intelecto determina e mantém firme as determinações"," enquanto que, "a razão é negativa e dialética, porque resolve em nada as determinações do intelecto; é positiva, porque cria o universal, e nele compreende o particular"; para Hegel, insistiu-se em considerar o intelecto de todo separado da razão, bem como a razão

\footnotetext{
Hegel, G. W. F. Ciencia de la Lógica. p. 36.

Hegel, G. W. F. Op. cit., p. 37.

Hegel, G. W. F. Op. cit., p. 38.

Hegel, G. W. F. Op. cit., p. 38.

Hegel, G. W. F. Op. cit., p. 38.

Hegel, G. W. F. Op. cit., p. 38.

Hegel, G. W. F. Op. cit., p. 38.
} 
dialética da razão positiva, entretanto, a razão é espírito, que está acima dos dois como razão inteligente ou intelecto racional.

Pois bem, é o espírito, portanto, o que constitui as qualidades tanto da razão dialética como do intelecto. Ele é o negativo, nega o simples e fundamenta assim a determinada diferença do intelecto, ao mesmo tempo a resolve e por isso é dialético e mais, ele é também o positivo e desta maneira restaura o primeiro simples, porém como um universal que é concreto em si mesmo, de modo que sob ele não se subsume um particular, senão que nesta definição e na solução da mesma o particular já se determinou.

Para Hegel, então, seria preciso empregar, desde o começo, um novo procedimento para expor o reino do pensamento de uma maneira filosófica. No entanto, é bom lembrar que o conteúdo da ciência da lógica se encontra como um material externo na metafísica e lógica anteriores, material este que na sua concepção havia sido tratado superficialmente e de uma forma não especulativa, de modo que este material, que consiste nas formas conhecidas de pensamento, é considerado necessário e importante, mesmo que às vezes esteja exposto em desordem nestas ciências.

Estas formas de pensamento, estão, antes de tudo, expostas e consignadas na linguagem do homem, portanto, "[...] tão natural é ao homem o elemento lógico, ou para melhor dizê-lo, tão próprio é de sua natureza mesma”. . Assim sendo, a linguagem penetra em tudo o que o homem representa, faz seu, por conseguinte, "[...] o que o homem converte em linguagem e expressa nela, contém escondida,

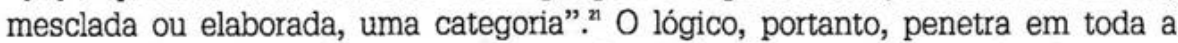
atividade do homem (sentir, necessitar, desejar) e o converte em algo humano, mesmo que seja de uma maneira formal, proporcionando-lhe representações e fins.

Nesta perspectiva, a filosofia não precisa de nenhuma terminologia especial, pois além da linguagem ordinária conter em si as determinações lógicas, o progresso da cultura e das ciências em particular promove gradativamente relações de pensamento mais elevadas. Entretanto, é bom lembrar que os objetos lógicos e suas expressões, apesar de conhecidos no mundo da cultura não são, por isso, reconhecidos; faz-se necessário, então, reconhecer este conhecido no pensamento natural e estabelecer suas relações com a ciência.

Hegel considera um grande progresso o fato das formas de pensamento terem sido liberadas da matéria em que estavam fundadas na intuição, bem como em nosso desejo, vontade e suas representações, e tenham sido postas em relevo por si e tenham se tornado objeto da reflexão por si, o que já é o começo do reconhecimento.

Ora, "[...] a exigência de se ocupar com pensamentos puros pressupõe um largo caminho que o espírito humano deve ter percorrido [... $]^{\text {ma }}$ e consiste, em abstrair a matéria da intuição, imaginação, desejo, vontade, etc. em que as determinações do pensamento estão enredadas. Deste modo, "a filosofia em geral tem,

Hegel, G, W. F. Op. cit., p. 42.

Hegel, G. W. F. Op. cit., p. 42.

Hegel, G. W. F. Op. cit., p. 44 e 45. 
todavia, que ocupar-se de objetos concretos - Deus, a natureza, o espirito - em seus pensamentos, mas a lógica trata deles só por si, em sua total abstração". ${ }^{\text {. }}$

$\mathrm{Na}$ própria vida, então, se passa o emprego das categorias, pois elas servem à atividade espiritual do conteúdo vivente, bem como na criação e intercâmbio das representações que a ela se referem. Desta forma, "[...] em parte as categorias servem como abreviaturas por sua universalidade [...]" e "em parte servem também para a mais exata determinação e descoberta de relações objetivas [...]", sendo que a verdade do pensamento que se mescla com elas se faz depender do existente mesmo.

O uso das categorias que se chama lógica natural é inconsciente. Assim, como muitas vezes estamos a serviço de nossos impulsos, paixões e interesses em vez de o possuirmos, "[...] estamos muito menos convencidos de que estejam a nosso serviço as formas de pensamento, que passam, através de todas as nossas representações [...]" Por conseguinte, "[...] muito menos podemos dizer que dominamos os conceitos das coisas, ou que as determinações do pensamento, cujo complexo elas representam, estejam a nosso serviço"."

Nesta perspectiva, na lógica natural a atividade do pensamento atua de forma inconsciente e este se encontra disperso numa matéria múltipla. Importa pois, purificar estas categorias que atuam somente de maneira instintiva e elevar por este meio o espirito à liberdade e à verdade, realizando a mais alta tarefa da lógica.

Ora, para Hegel, quando nos perdemos nas sensações, desejos, etc., só podemos encontrar a liberdade e sair de tal posição, na certeza de si mesmo, na pura abstração do pensamento. Assim, portanto, é o pensamento o nosso ato mais íntimo e o conceito objetivo das coisas constitui sua natureza, e isto porque "a coisa, sem dúvida, não pode ser para nós mais que o conceito que dela temos", de modo que, quando queremos falar das coisas, denominamos conceito (seu conceito) à natureza e essência delas.

Podemos perceber, portanto, que Hegel se contrapõe ao ponto de vista que concebe as determinações do pensamento como forma exterior. Contrapõe-se, por conseguinte a Kant quando este concebe o pensamento como um meio entre nós e as coisas, de tal forma que este meio mais nos distancia delas, pois a coisa em si permanece distante de nós e de nosso pensamento sobre elas,

Ora, para Hegel, a própria coisa em si é um objeto do pensamento, ou seja, é ainda um objeto do pensamento da abstração vazia. Para ele, o fundamento indispensável, o conceito, o universal, que é o pensamento mesmo, não deve ser considerado só como uma forma indiferente que esteja num conteúdo.

Pois bem, para Hegel, tratar previamente os conceitos, as determinações do pensamento, como formas distintas da matéria, se manifesta como um procedimento inadequado para a verdade, pois "[...] os conceitos considerados assim,

2 Hegel, G. W. F. Op. cit., p. 45.

${ }^{24}$ Hegel, G. W. F. Op. cit., p. 45.

3 Hegel, G. W. F. Op. cit., p. 46

* Hegel, G. W. F. Op. cit., p. 46.

Hegel, G. W. F. Op. cit., p. 47.

Hegel, G. W. F. Op. cit., p. 47. 
como puras formas, distintas do conteúdo, se aceitam como fixados numa determinação que lhes dá um aspecto de algo limitado e os faz incapaz de abarcar a verdade $[. .] " .$.

Para Hegel, as categorias formais, em sua esterilidade, foram abandonadas com desprezo a uma lógica e metafísica escolares, sem que se tenha dado conta de que na lógica natural e na recusa do reconhecimento das determinações do pensamento ficava-se prisioneiro do pensamento inadequado. Entretanto, para ele, embora que se tenha recusado a concepção formal do pensamento e suas leis, continuava-se praticando-as, como é o caso da determinação formal, comum a tais formas, que é a identidade, a qual se afirma como lei na lógica deste conjunto, como principio de contradição $(\mathrm{A}=\mathrm{A} e=$ de não- $\mathrm{A})$.

Ora, é compreensão de Hegel que a imperfeição desta forma de pensamento pode ser superada quando na consideração do pensamento se considera não só a forma dita exterior, más também o conteúdo. Nesta perspectiva, "ao introduzir [...] o conteúdo na consideração lógica, não são as coisas, senão o essencial, o conceito das coisas, o que se converte em objeto final". ${ }^{.0}$

Pois bem, o conceito não é representado ou intuído de maneira sensorial, ele é o produto e o objeto do conteúdo pensamento e é a coisa em si e para si, o logos, a razão do que é, a verdade que leva o nome das coisas. Deste modo, “[...] o logos é, de tudo, o que menos deve ser excluído da ciência da lógica. Por isso, não pode depender do arbítrio introduzi-lo ou excluí-lo da ciência"s:

As determinações do pensamento, consideradas como formas exteriores, têm portanto, sua verdade no conceito. Por conseguinte, a ciência da lógica será também a reconstrução das determinações do pensamento que foram postas pela reflexão e fixadas como formas exteriores ao conteúdo. Deste modo, no sistema da lógica estas categorias deverão encontrar o seu lugar e determinação, pois é exigência do pensamento lógico averiguar se há um conteúdo sem forma ou forma sem conteúdo, algo interior sem exterioridade, ou uma exterioridade sem interioridade, etc.

Podemos concluir, portanto, que para Hegel, consistia uma necessidade para a filosofia e a ciência em geral repensar a lógica através de um novo procedimento metodológico e com isso restituir-lhe seu papel essencial para a efetivação da ontologia, da ciência efetiva, capaz de dar conta do real.

\section{2 - Sobre o começo da ciência lógica no pensamento de Hegel}

Só nos tempos modernos se percebeu que é dificil achar um começo para a filosofia. Surgiram, então, questões como: o começo da filosofia é mediato ou imediato?, subjetivo ou objetivo?

Pois bem, o pensamento abstrato se interessava pelo princípio considerado como conteúdo designado de certo modo (a água, o uno, o novo, a idéia, etc.), mas, com o progresso da cultura e da ciência, surgia necessidade de um critério

Hegel, G. W. F. Op. cit., p. 49-50.

Hegel, G. W. F. Op. cit., p. 51.

Hegel, G. W. F. Op. cit., p. 52. 
objetivo e o pensamento se volta para o comportamento do conhecer, de modo que a atividade subjetiva é considerada como um momento essencial da verdade objetiva.

Ora, qual deve ser o começo da ciência? é uma das questões fundamentais para o pensamento de Hegel. Para ele, "[...] a natureza do conhecer é tratada em geral dentro da ciência da lógica, e o mesmo conhecer na sua ulterior forma concreta pertence a ciência do espírito e a sua fenomenologia"s e isto implica, que não podemos antes da ciência pôr a claro o referente ao conhecimento e menos ainda ao método científico, pois seria querer fazer ciência antes da ciência.

Nesta perspectiva, a lógica pressupõe a fenomenologia do espírito, pois o seu elemento e seu começo é o puro saber, que é a última verdade da consciência. $\mathrm{Na}$ exposição da fenomenologia a consciência imediata é o início para a ciência, pois "nesta ciência do espírito em suas manifestações, se parte da consciência empírica, sensivel; e esta é o verdadeiro saber imediato". ${ }^{x}$ Porém, esta ciência da consciência tem como resultado final o conceito de ciência e este é o puro saber; portanto, a lógica pressupõe a ciência do espirito fenomenológico, pois a lógica pressupõe o que naquela consideração se mostrou como resultado, isto é, o puro saber.

Neste horizonte, "a lógica é a ciência pura, isto é, o saber puro na amplitude

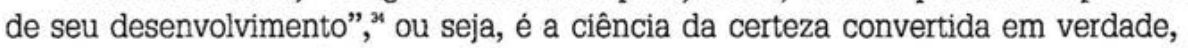
a certeza que não está frente ao objeto, mas o converteu em interior e o conhece como a si mesma. Deste modo, então, "o saber puro [...] eliminou toda a relação com o outro e com toda a mediação; é o indistinto. Por conseguinte, este indistinto cessa de ser ele mesmo saber; só permanece presente a simples mediação". ${ }^{30}$

Para Hegel, esta simples imediação em sua verdadeira expressão é o puro ser, o qual não deve significar mais que o ser como tal, totalmente abstrato, assim como o puro saber não deve significar mais que o saber em geral, abstrato. 0 começo da ciência, portanto, tem que ser um começo abstrato, tem que ser algo imediato, ou o imediato mesmo. $\mathrm{O}$ começo, é por conseguinte, o puro ser, pois não deve pressupor nada, ser mediado por nada, nem ter um fundamento e sim ser ele mesmo o fundamento de toda a ciência.

Ora, em filosofia “[...] o avançar é um retroceder ao fundamento, ao originánio e verdadeiro, do qual depende o principio com que se começou e pelo qual é em realidade produzido" $\mathrm{e}$ isto, porque o princípio não é algo arbitrário, mas se constitui, em parte, na verdade e em parte, na verdade primeira; assim, portanto, o último fundamento surgido do primeiro é também aquele de onde surge o primeiro.

Neste horizonte, o começo da filosofia é o fundamento presente e perdurável em todos os desenvolvimentos necessários e permanece imanente ao desenvolver de suas determinações. Deste modo, o avançar é apenas uma determinação ulte-

\footnotetext{
Hegel, G. W. F. Op. cit., p. 89.

Hegel, G. W. F. Op. cit., p. 89.

Hegel, G. W. F. Op. cit., p. 89.

Hegel, G. W. F. Op. cit., p. 90.

Hegel, G. W. F. Op. cit., p. 92.
} 
rior do começo, que não desaparece e continua fundamentando o que se segue, portanto, "para a ciência o essencial não é tanto que o começo seja um imediato puro, senão que o seu conjunto seja um recorrer circular em si mesmo, em que o primeiro se tornou o último e o último o primeiro"."

Assim sendo, o começo, mediante 0 avanço, perde o que tem de unilateral, deixa de ser imediato e se converte em mediato, pois o que só é começo não está desenvolvido e carece de conteúdo. Daí porque podemos concluir que só a ciência em seu pleno desenvolvimento conduz ao conhecimento completo, ou seja, rico em conteúdo e verdadeiramente fundado.

Para Hegel, “[...] todas as pressuposições devem encontrar sua solução na ciência mesma"." Ora, foi a própria ciência que assinalou que na ciência pura se começa com o ser puro, o qual é a unidade em que se movimenta o saber puro. Este ser puro é um imediato absoluto, uma indeterminação pura, mas que resulta de num mediato absoluto, numa determinação.

Nesta perspectiva, "[...] o começo, como começo do pensar, deve ser totalmente abstrato, universal, forma pura sem nenhum conteúdo", entretanto, "o começo, não é o nada puro, senão o nada do qual tem que surgir algo; logo, também o ser está já contido no começo"." Ora, é deste modo que o começo encerra já em si uma contradição não desenvolvida e nem resolvida, pois "o começo contém, em conseqüência, a ambos: o ser e o nada, é a unidade do ser e o nada; isto é, é um não-ser que ao mesmo tempo é ser, é um ser que ao mesmo tempo é nãoser"."

Pode-se dizer, então, que os contrários ser e não-ser estão no começo como uma união imediata e o começo é uma unidade indiferenciada, porém, ao mesmo tempo, "[...] o ser e o nada existem no começo como diferentes, pois o começo assinala algo distinto", ${ }^{2}$ logo, diferenciado.

Nesta perspectiva, para Hegel, o começo contém a unidade do ser distinto e do ser indistinto, da identidade da identidade com a não identidade, ou seja, a própria contradição. Ora, esta definição do começo é considerada por Hegel a mais pura e abstrata do absoluto, de modo que o começo da ciência da lógica e todas as outras suas determinações e desenvolvimentos seguintes serão determinações mais ricas deste absoluto, logo, da própria lógica enquanto lógicaontológica.

\section{3 - Introdução ao conceito geral de lógica-ontológica na concepção de Hegel}

Para Hegel, "na lógica mais que em nenhuma outra ciência se sente a necessidade de começar pelo objeto mesmo, sem reflexões preliminares" $\mathrm{e}$ isto, porque

\footnotetext{
Hegel, G. W. F. Op. cit., p. 92.

Hegel, G. W. F. Op. cit., p. 91.

Hegel, G. W. F. Op. cit., p. 95.

Hegel, G. W. F. Op. cit., p. 95.

4 Hegel, G. W. F. Op. cit., p. 95.

42 Hegel, G. W. F. Op. cit., p. 95.

13 Hegel, G. W. F. Ciencia de la Lógica, p. 57.
} 
nas outras ciências o objeto das mesmas e o método científico se diferenciam um do outro. Assim sendo, estas ciências, diferentemente da lógica, podem adotar diretamente as formas das definições pressupostas como conhecidas e aceitas, e servir-se da maneira ordinária de raciocinar para estabelecer seus conceitos gerais e suas determinações fundamentais.

A lógica, entretanto, não pode pressupor nenhuma destas formas de reflexão ou regras e leis do pensamento, pois elas têm que ser fundamentadas na própria lógica e constituem parte de seu conteúdo. Desta forma, “[...] não só a exposição do método científico pertence ao conteúdo da lógica, senão também o conceito mesmo da ciência em geral [...]"," de modo que só a sua completa exposição permite dizer o que ela é e mais, o pensamento que a concebe como seu objeto engendra seu conceito no curso da lógica, o que the impede de ser definido previamente.

Entretanto, aceita-se que a lógica ao estudar o pensamento e suas leis faz abstração de todo conteúdo e que este pertence a um conhecimento da matéria, que não seria objeto da lógica, sendo, portanto, independente da mesma. Assim, a lógica deveria somente apresentar as condições formais do pensamento verdadeiro e não um conhecimento do real, nem tão pouco um caminho para alcançar a verdade real, pois o conteúdo, o elemento da verdade, estaria fora dela.

Ora, Hegel se contrapõe a esta concepção formal da lógica. Ele se contrapõe, primeiramemte, porque "[...] é inapropriado dizer que a lógica faz abstração de qualquer conteúdo, que ensina só as regras do pensar sem penetrar no que foi pensado e sem considerar sua natureza". "Para ele, ao tratar de seu objeto, o pensamento e as regras do pensar, a lógica tem também o segundo elemento do conhecimento, a saber, a matéria; nesta perspectiva, para Hegel, as representações em que se assentavam o conceito de lógica deveriam desaparecer de todo, de modo que, esta ciência seja concebida de um modo mais elevado.

Ora, se supunha que o conceito de lógica se fundava na separação do conteúdo e da forma deste, isto é, na separação entre certeza e verdade. Pois bem, assim sendo, os dois elementos, o objeto e o pensamento, são colocados em ordem hierárquica, de modo que, o objeto é considerado algo em si, completo, acabado, que pode prescindir do pensamento e o pensamento, como algo imperfeito, que deve amoldar-se a uma matéria como uma forma indeterminada.

Neste horizonte, o qual é contraposto por Hegel, a verdade seria a concordância do pensamento com o objeto e este deveria amoldar-se a ele. Assim, portanto, o pensamento e o objeto eram concebidos como duas esferas distintas, de modo que o pensamento não sairia de si até o objeto e este seguiria sendo uma coisa em si mesma, para além do pensamento; Podemos dizer, então, que para Hegel estas opiniões sobre a relação sujeito e objeto expressam determinações de uma consciência ordinária que, quando transladadas à razão se convertem em erros, que por obstruirem o acesso à filosofia devem ser abandonados no umbral da mesma.

" Hegel, G. W. F. Op. cit., p. 57.

* Hegel, G, W. F. Op. cit., p. 57 
É a partir desta compreensão que Hegel considera que a metafísica tinha uma compreensão muito mais elevada que a compreensão corrente em seus dias, pois ela partia da premissa de que o que conhecemos pelo pensamento sobre as coisas constitui o que elas têm de verdadeiro. Nela, portanto, há uma coincidência na qual o pensamento em suas determinações imanentes e a natureza das coisas constituem um só e mesmo conteúdo, de modo que, a metafísica tinha uma visão mais especulativa das coisas, pois:

“[...] esta metafisica [...] estimava que o pensamento e as determinações do pensamento não eram algo estranho ao objeto, senão que constituiam mais ainda a sua essência, ou seja, as coisas e o pensamento delas [...] coincidem em si e por si [...]".

Para Hegel, porém, apesar do ponto de partida especulativo da metafisica "[...] o entendimento reflexivo se apoderou da filosofia". Pois bem, devemos entender com isso que a filosofia ficou a mercê do entendimento que abstrai e, portanto, separa e insiste em suas separações. Ora, este entendimento se contrapõe à razão, pois

\begin{abstract}
“[...] se comporta como o intelecto humano comum, e faz prevalecer sua maneira de ver, segundo a qual a verdade teria por base a realidade sensível, as idéias não seriam mais que idéias, no sentido de que só a percepção sensível lhes daria conteúdo e realidade, e que a razão, ao permanecer em si e por si, cria somente ilusões"."
\end{abstract}

Para Hegel, a adesão ao entendimento é compreendida como uma renúncia de si mesma da razão, renúncia na qual a verdade se perde, se vê reduzida à aparência, ou seja, a algo que não corresponde à realidade dos objetos, de modo. que o saber se reduz à opinião; entretanto, esta representação se generalizou devido à necessária contradição das determinações do intelecto para consigo mesmas.

Ora, o intelecto ao tentar relacionar suas determinações divisórias se depara com a contradição, mas não consegue levá-las a cabo pois esta relação da reflexão pertence só à razão, que é quem tem a capacidade de elevar-se acima das determinações isoladas. Pois bem, para Hegel, “[...] a contradição é justamente a elevação da razão sobre as determinações do intelecto e a solução das mesmas" e mais, "[...] esta investigação, se não se realiza de maneira acabada, cai no erro de apresentar as coisas como se a razão estivesse em contradição consigo mesma". .

Pode-se dizer, então, que o intelecto, por não conseguir dar um passo adiante na solução de suas contradições, refugiou-se na existência sensorial crendo encontrar nela um objeto sólido. $O$ intelecto, por conseguinte, pressupôs que não podemos conhecer as coisas em si, mas só a sua aparência, o fenômeno, e reduziu, deste modo, o saber a um conhecimento das aparências. No entanto, para Hegel, "[...] absurdo é um verdadeiro conhecimento, que não conhece um objeto tal qual é em si”."

\footnotetext{
* Hegel, G. W. F. Op. cit., p. 60.

- Hegel, G. W. F. Op. cit., p. 60.

Hegel, G. W. F. Op. cit., p. 60-61.

Hegel, G. W. F. Op. cit., p. 61.

so Hegel, G. W. F. Op. cit., p. 61.

s) Hegel, G. W. F. Op. cit., p. 63.
} 
Ora, as formas lógicas quando tratadas como determinações firmes e portanto, desligadas, são formas mortas, carentes de conteúdo sólido, de matéria. Pois bem, a critica das formas do intelecto concluiu que ditas formas não se aplicam às coisas em si, entretanto, dita crítica não efetuou nelas nenhuma modificação.

Para Hegel, o fato de a crítica do intelecto conceber as formas lógicas como vazias de conteúdo deveria significar que tais formas não são em si algo verdadeiro e, também, que não são suficientes para dar conta das coisas, de modo que o intelecto deveria recusar-se acomodar-se a elas.

Entretanto, a crítica do intelecto se aferrou a ditas formas sem tratá-las adequadamente, ou seja, tal crítica não considerou estas formas segundo seu peculiar conteúdo e as aceitou no sujeito, tal como as encontrou; e isto significa que esta critica "não pode falar de uma dedução das formas em si mesmas ou de uma dedução delas como formas subjetivas; muito menos [...] pode falar de sua consideração dialética".".2.

Para Hegel, portanto, a lógica parece carente de conteúdo não por causa de seu objeto, mas pela maneira com que este foi concebido. Assim, a lógica não é uma ciência desprovida de conteúdo, pois "a carência de conteúdo das formas lógicas se encontra somente na maneira de considerá-las e tratá-las", ${ }^{\infty}$ de modo que se faz necessário, então, considerar o objeto da lógica e a própria lógica diferente.

Hegel apresentou na fenomenologia do espirito a consciência em seu movimento progressivo, movimento este que passa por todas as formas de relações com o objeto e tem como resultado o conceito de ciência. Ora, a ciência pressupõe a liberação com relação à oposição da consciência, portanto, "ela contém o pensamento, enquanto este é também a coisa em si mesma, ou contém a coisa em si, enquanto esta é também o pensamento puro", de onde podemos concluir que o pensamento objetivo constitui o conteúdo da ciência pura.

Pois bem, é nesta perspectiva que a ciência não pode ser vista como formal e nem desprovida de conteúdo, mas com uma matéria cuja forma não é algo exterior e , portanto, é pensamento puro. Assim, então, “[...] a lógica tem que ser concebida como o sistema da razão pura, como o reino do pensamento puro. Este reino é a verdade tal como está em si e por si, sem envoltura", " pois não se trata de um pensamento em torno de algo que existe fora do pensamento; podemos concluir, então, que as determinações próprias do pensamento são o conteúdo e a verdade mesma, e isto significa que a verdade de algo está somente no seu conceito.

Ora, para Hegel, a filosofia crítica já transformou a metafísica em lógica, porém, deu às determinações lógicas um aspecto essencialmente subjetivo, o que fez com que as determinações se afastassem do objeto, o qual permanecia como uma coisa em si inacessível. Pois bem, apesar disso, Kant considerou a lógica afortunada por ter tido um acabamento precoce, já com Aristóteles.

Hegel, porém, considera que se desde Aristóteles na lógica não se efetuou modificações, isto leva à conclusão de que esta ciência necessita com mais razão

\footnotetext{
Hegel, G. W. F. Op. cit., p. 63.

Hegel, G. W. F. Op. cit., p. 63.

Hegel, G. W. F. Op. cit., p. 63.
} 
de uma reelaboração total. Para ele, "em realidade, faz muito tempo que se vem experimentando a necessidade de uma transformação da lógica", " pois no estado em que se encontrava a lógica nela tinham-se apenas indícios do método científico e mais, não foi sem razão que equiparou-se sua maneira de pensar ao cálculo matemático e de tal modo, que no juízo e na dedução suas operações foram reduzidas principalmente ao lado quantitativo das determinações e se converteram num procedimento analítico, num cálculo carente de conteúdo.

Ora, alguns filósofos se deixaram fascinar pela idéia de aplicar dito método à filosofia, o que para Hegel é contraditório pois seria converter o processo extrínseco da quantidade carente de conceito em processo do conceito. Podemos observar, pois, que "[...] a filosofia não havia encontrado ainda seu método" e tentava tomar emprestado o método das ciências.

Hegel, porém, não concorda com isso, pois “[...] a expressão daquele que só pode ser a verdadeiro método da ciência filosófica, pertence ao trabalho da lógica mesma" e a filosofia se tem que ser ciência, não pode tomar emprestados, para este fim, métodos das ciências e sim, caminhar por caminhos que ela constrói por si mesma.

Para Hegel, "a única maneira de lograr o progresso científico [...] é o reconhecimento da proposição lógica que afirma que o positivo é por sua vez o negativo ou que o contraditório não se resolve em um zero, num nada abstrato, senão só na negação de seu conteúdo particular", ${ }^{\text {s }}$ sendo então, uma negação determinada; deste modo, no resultado está contido aquilo do qual resulta, sendo ele apenas uma negação determinada e por isso com conteúdo e mais, sendo também um novo conceito superior, mais rico que o precedente, já que se enriqueceu com a negação de seu contrário e por conseguinte, o contém como algo mais que ele, ou seja, como a verdade de si e de seu contrário.

Podemos dizer, portanto, que para Hegel, "aquilo por cujo meio o conceito se impele adiante por si mesmo é o negativo [...] que contém em si; este é o verdadeiro elemento dialético" Neste horizonte, a dialética, que foi considerada como uma parte fora da lógica, obtém uma posição completamente diferente da que tinha quando era considerada como um comportamento extrínseco que não pertence à coisa em si mesma.

Pois bem, para Hegel, com este procedimento dialético há de formar-se, em geral, o sistema dos conceitos, o qual deve ser complementado por um curso incessante, sem que seja introduzido nada do exterior e mais, nenhuma exposição será científica se não seguir o curso deste método, que é o curso da coisa mesma, pois ele não é distinto de seu objeto e conteúdo, já que é o conteúdo em si que na sua dialética o impele adiante.

Na concepção de Hegel, o grande mérito de Kant foi ter elevado a dialética e a apresentado como uma operação necessária da razão, o que já se contrapõe à

\footnotetext{
Hegel, G. W. F. Op. cit., p. 68. Hegel, G. W. F. Op. cit., p. 70. Hegel, G. W. F. Op. cit., p. 70.

Hegel, G. W. F. Op. cit., p. 71.

Hegel, G. W. F. Op. cit., p. 73.
} 
posição que afirma que a dialética é um jogo falso, um ato arbitrário. Ora, foi Kant quem enfatizou a necessidade da contradição e mostrou que ela pertence às determinações do pensamento; para Kant, porém, dialética nos conduz a antinomias insolúveis que trazem como resultado a afirmação de que através da razão somos incapazes de ter acesso às coisas como elas são em si mesmas.

Para Hegel, entretanto, "[...] as exposições dialéticas de Kant, nas antinomias da razão pura, não merecem muitos elogios quando examinadas cuidadosamente [...] ${ }^{3 \%} \mathrm{e}$ isto, porque o especulativo está neste momento dialético, do qual resulta dos contrários a unidade diferenciada, o que não foi compreendido por Kant.

Podemos concluir, então, que para Hegel, esta dialética da razão é o único método científico, o verdadeiro método científico, o qual nos possibilita superar as determinações fixas do entendimento e com isso sair do reino das aparências para a realidade das coisas como são em si, pois este movimento dialético é imanente ao próprio real, é a própria natureza do real.

\section{3 - A ontologização da lógica em Hegel como meta-crítica à crítica kantiana à ontologia clássica}

\section{1 - A crítica kantiana à ontologia clássica}

A filosofia surge no ocidente com uma pergunta pelo real enquanto totalidade, ou seja, a filosofia surge como ontologia ou teoria do ser. Pois bem, perguntar pelo real enquanto totalidade significa perguntar pelo que constitui a realidade enquanto unidade, ou seja, perguntar pelo idêntico nas diferentes manifestações do real.

A filosofia grega pensou a totalidade do real como "cosmos". Pode-se dizer, então, que o pensamento clássico se situa num horizonte cosmocêntrico objetivista e isso significa dizer que o modelo de ser a partir de onde tudo é pensado e recebe determinações é a ordem imutável do todo entendido como cosmos. Para Manfredo Oliveira: "O grego, no princípio de nossa cultura, interpreta o real como "cosmos", isto é, como um todo ordenado, como ordem em contraposição à desordem, à indeterminação, ao caos [...]";" Podemos dizer, então, que no mundo grego a tarefa do pensamento era tematizar esta ordem, considerada fundamento do conhecimento e da ação do homem.

A "fisiologia", tentando dar uma imagem sensivel à totalidade, representa os primeiros ensaios na tematização deste todo, tematização esta que se fazia buscando um princípio ou princípios de onde emergem as determinações do real. Assim, temos como fundamento originário a água (Tales), 0 apeiron (Anaximandro), o ar (Anaximenes), etc. A fisiologia não pergunta ainda pelo lugar que o ente ocupa na estrutura do todo, mas apenas pelo todo; será tarefa da metafísica perguntar pelos entes na estrutura do todo.

A metafísica responderá a esta pergunta através da teoria das essências, sendo estas o que de permanente se conserva nas coisas, através de suas mudanças.

Hegel, G. W. F. Op. cit., p. 73.

51. Revista Sintese, $n^{\circ} 33$, p. 38. 
Assim, a metafísica, enquanto ontologia, representa a tentativa de não só tematizar o todo da realidade e seu princípio, mas também tematizar o lugar que os entes ocupam neste todo.

Segundo Aristóteles: "Há uma ciência que investiga o ser como ser e os atributos que lhe são próprios em virtude de sua natureza" . Esta ciência é a metafisica ou ciência primeira, ou ontologia, que não estuda o ser em particular, mas o ser enquanto tal. $\mathrm{O}$ mesmo compreende a metafisica como uma ciência que estuda o real em si e que deduza de algum princípio central a natureza detalhada do universo.

Porém, uma pergunta fundamental ocupa Aristóteles na metafísica, a saber: o que torna possivel a metafísica como ciência? Ora, "a ciência emergiu, na cultura ocidental, como ciência da natureza e encontrou na cultura grega a sua sistematização em Aristóteles" e seu pressuposto fundamental é que existe uma natureza imutável que se determina por uma essência imutável, a qual o cientista é capaz de captar através da razão e atua de forma eminentemente contemplativa diante de uma verdade que se encontra no objeto, no ser.

Neste sentido, quem estuda o ser deve estudar os princípios que a ele pertencem e o principio mais certo do ser é a lei de contradição, a qual, se enuncia assim: "O mesmo atributo não pode, ao mesmo tempo, pertencer e não pertencer ao mesmo sujeito com relação à mesma coisa [...]"."

Deste modo, para Aristóteles, dois aspectos tornam possivel a metafísica enquanto ciência do real, ontologia: primeiro, o fato de que "tudo o que é, possui uma certa natureza que lhe pertence apenas como ser, e isso pode ser conhecido", ${ }^{\text {, }}$ pois "[...] do próprio não ser dizemos que é não ser" . Segundo, o fato de que "existem certos principios verdadeiros de tudo o que é, os quais estão na base de toda a demonstração - as leis de contradição e do terceiro excluído"."

A lei de contradição tem, portanto, um caráter ontológico. A mesma é vista como uma lei fundamental do ser, pois "[...] é impossivel que asserções contraditórias sejam ao mesmo tempo verdadeiras da mesma coisa [...]"; ${ }^{\infty}$ entretanto, esta lei é vista como uma lei fundamental também do pensamento, da lógica ou ciência do pensar correto e isto significa dizer que nem no pensamento, nem no real, existe a contradição; significa dizer, então, que o ser sendo idêntico a si não contém a sua negação e que nós não podemos pensar o ser com a negação, mas somente com a identidade.

Ora, o princípio de identidade, o qual afirma que todo ser é idêntico a si, exclui do ser a negação e afirma a lei da contradição e também a lei do terceiro excluído, que excluem a contradição no processo de predicação ou conhecimento. Neste horizonte, podemos dizer que estas leis ou princípios se implicam mutua-

${ }^{62}$ ARTSTÓTELES. A Metafisica. Livro IV, p. 87.

๗ OLIVEIRA, Manfredo. A diferença entre Ciência Tradicional e Ciência hoje.

a ARISTÓTELES. Op. cit., p. 92.

* ROSS, David. Aristóteles. p. 162.

* ARISTÓTELES. Op. cit. , p. 68.

ROSS, David. Op. cit., p. 162.

* ARISTÓTELES. Op. cit., p. 106. 
mente e determinam que o pensamento (a lógica), o ser (o real) e o conhecimento do ser (ontologia) se estabelecem, pela exćlusão da contradição.

Segundo Aristóteles, "[...] é impossivel que sejam verdadeiras a um tempo a afirmação e a negação, impossivel também, é a coexistência de contrários no mesmo sujeito [...]"; e mais, "[...] por outro lado, não pode haver um termo médio entre contraditórios, mas de um só sujeito ou devemos afirmar ou negar qualquer predicado que seja".

Ora, Aristóteles sistematizou os princípios fundamentais que nortearam o pensamento anterior e posterior a si até Hegel, e nesta sistematização tanto o ser (o real) como o pensamento (o lógico) carecem da contradição. O ser carente de contradição é o ser do princípio da identidade, o ser idêntico a si, o ser que exclui a negação e, portanto, o movimento.

Nesta perspectiva, a essência do real é vista como o ser sem movimento, o ser substancial e imutável, a forma ou o não sensível. Ora, isto não significa dizer que não há movimento, significa dizer que o movimento expressa apenas a aparência do ser e não a sua essência imaterial e imutável, que é o primado fundamental na determinação do ser. Assim, é o universal, imaterial e imutável, abstraído da particularidade e mutabilidade do sensivel, que é posto como fundamento do real.

Podemos dizer, portanto, que foi Aristóteles quem sistematizou os princípios fundamentais que alicerçaram a ontologia clássica, porém, a Filosofia kantiana se incumbiu da tarefa de realizar a crítica e a negação da ontologia.

Pois bem, Kant fez uma reflexão sobre a metafísica de Aristóteles e, portanto, sobre toda a ontologia clássica, de forma que esta sofre uma transformação radical. Ora, para Manfredo Oliveira, "entender esta reforma da 'Metafísica clássica' em Kant significa entender a transformação da 'metafísica' em 'filosofia transcendental', que tem na lógica transcendental o seu centro";" neste horizonte, a questão fundamental para Kant é indagar pela cientificidade do saber metafísico, ou seja, indagar se é possivel estabelecer a via segura da ciência para os conhecimentos pertencentes ao dominio da razão.

Nesta perspectiva, Kant afirma que a matemática e a física atingiram o caminho seguro da ciência, pois "[...] no admirável povo grego, a matemática entrou na via segura da ciência", e mais, "a física foi ainda mais lenta em encontrar a estrada larga da ciência. Só há século e meio [...]". ${ }^{n}$ Ora, para Kant isso ocorreu devido a uma revolução no modo de pensar, a qual afirma que nós devemos conhecer mediante princípios a priori e "[...] que para conhecer, com certeza uma coisa a priori nada deve atribuir-lhe senão o que fosse consequêencia necessária do que nela tinha posto, de acordo com o conceito". ${ }^{\text {s }}$

Pois bem, os físicos compreenderam que se deve procurar na natureza o que a razão nela põe e dela apreender o que por si só não alcançaria saber. Assim, a

ARISTOTELES. Op. cit., p. 106.

ARISTÓTELES. Op. cit., p. 107.

OLIVEIRA, Manfredo. Lógica Transcendental e Lógica Especulativa. Cadernos da UNB 6, 7 e 8.

KANT, Immanuel. Crítica da Razão Pura. p. 17.

KANT, Immanuel. Op. cit., p. 17. 
razão se dirige à natureza com os seus princípios que determinam os seus juízos segundo leis constantes e são os princípios da razão que podem dar aos fenômenos a autoridade de leis, sendo que a experimentação se dirige à natureza para que a razão a julgue. A razão é, pois, o juiz que pede à natureza que lhe responda.

Para Kant, "o destino não foi até hoje tão favorável que permitisse trilhar o caminho seguro da ciência à metafísica [...]"." Ora, a metafísica é um conhecimento da razão à parte e acima da experiência e opera mediante simples conceitos. Para Kant, então, "não há dúvida, pois, que até hoje o seu método tem sido um mero tacteio e, o que é pior, um tacteio apenas entre simples conceitos". ${ }^{\text {. }}$

Kant investiga, então, se é possivel estabelecer o modelo de saber da matemática e da física para a metafísica com o intuito de elevá-la à ciência. Ora, a metafisica pensava que o nosso conhecimento deveria ser regulado pelos objetos e que através da razão poderíamos contemplar a verdade do objeto, ou essência. $\mathrm{Na}$ concepção kantiana isso impedia de se descobrir a priori, mediante conceitos, algo que ampliasse nosso conhecimento, dai por que, importa, pois, melhor resolver as tarefas da metafísica.

Kant o fez, admitindo que os objetos devem se regular pelo nosso conhecimento e não o nosso conhecimento pelos objetos, como na metafísica, o que possibilitaria sabermos a possibilidade de um conhecimento a priori. Kant também tenta o mesmo no que diz respeito à intuição e aos conceitos, a saber, os objetos devem se guiar por nossa intuição e conceitos e não o contrário.

Nesta perspectiva, Kant aponta para a necessidade de uma ciência que determine a possibilidade, os princípios e a extensão de todo o conhecimento a prio$n$, pois há certos conhecimentos que mediante conceitos aparentam estender os nossos juízos para além dos limites da experiência.

Ora, é aqui que se situam as investigações da nossa razão, geralmente considerados mais importantes do que o entendimento pode nos ensinar no campo dos fenômenos. Pois bem, "estes problemas inevitáveis da própria razão pura são Deus, a liberdade e a imortalidade $[. . .]^{\prime m}$ e a ciência que os investiga é a metafisica.

Quanto ao método da metafísica, Kant afirma que: "o seu proceder metódico é, de início, dogmático, isto é, aborda confiadamente a realização de tão magna empresa, sem previamente examinar sua capacidade ou incapacidade". ${ }^{n}$ Importa, pois, saber como na metafísica o entendimento, abandonando o terreno da experiência, atinge seu conhecimento a priori e qual a sua extensão e limites, e o valor que possuem.

A crítica da razão pura terá a tarefa de alterar o método da metafísica segundo o exemplo dos geômetras e dos físicos, operando nela uma revolução completa. Ela é, pois, "[...] um tratado acerca do método, não um sistema da própria ciência; porém, circunscreve-se totalmente, não só descrevendo um contorno dos seus

\footnotetext{
KANT, Immanuel. Op. cit., p. 18.

KANT, Immanuel. Op. cit., p. 19.

KANT, Immanuel. Op. cit., p. 40.

KANT, Immanuel. Op. cit., p. 40.
} 
limites, mas também toda a sua estrutura interna". "Kant quer, portanto, delinear um plano total de um sistema da metafísica, o que é possivel à razão, pois, "[...] a razão pura especulativa tem em si mesma a particularidade de medir exatamente a sua capacidade em função dos diversos modos como escolhe para o pensar [...]".

Assim, então, a primeira parte da critica da razão pura tem a tarefa de explicar a possibilidade de um conhecimento a priori e dotar de provas as leis a priori que fundamentam a natureza enquanto objeto da experiência, o que na sua concepção seria impossível com o método anterior. Já a segunda parte tratará da impossibilidade de se ultrapassar os limites da experiência, o que é uma questão vital para a metafísica.

Pois bem, Kant procura demonstrar que nosso conhecimento se refere apenas aos fenômenos e não às "coisas em si", pois os princípios da razão pura têm como limites a sensibilidade, de modo que não podemos conhecer o supra-sensivel, ou essência, como pretendia a metafísica clássica.

Na parte analítica da crítica da razão pura Kant demonstrará que espaço e tempo são formas da intuição sensivel, ou seja, condição da existência das coisas enquanto fenômenos e que só possuímos conceitos do entendimento, logo, juízo, conhecimento, quando nos for dada a intuição correspondente a estes conceitos. A partir daí, se conclui que não podemos conhecer os objetos como "coisa em si", mas apenas como objetos de intuição sensivel. A razão, entretanto, quer ultrapassar estes limites, pois

"Com efeito, o que nos leva necessariamente a transpor os limites da experiência e de todos os fenômenos, é o incondicionado, que a razão exige necessariamente e com plena legitimidade nas coisas em si, para tudo o que é condicionado, a fim de acabar, assim, a série de condições" ${ }^{\infty}$

Ora, a totalidade é para Kant incognoscivel, pois ele separa o "em si" e o "para si", a "essência" e o "fenômeno", limitando-nos a só podermos conhecer as coisas enquanto fenômeno e não como elas são em si mesmas, ou seja, como essência. Assim, todas as vezes que a razão tenta pensar o todo, ou seja, todas as vezes que a razão pura assenta-se sobre raciocínios dialéticos, cai em contradição. Estas contradições são as antinomias, os paralogismos da razão pura, nos quais se pode afirmar e negar a proposição com o mesmo grau de consistência, de modo que estas contradições são insolúveis.

Após o exposto, podemos concluir que para Kant é impossivel a ontologia enquanto ciência. Ora, a metafísica por excluir do real e do pensamento sobre o real, a contradição, nos distanciou do real e do pensamento sobre o real, nos levando a pensar o real essencialmente como substância imóvel, portanto, sem processo, sem contradição; por sua vez, o pensamento kantiano por excluir a contradição do pensamento sobre o real, nega o caráter ontológico do conhecimento, nega que a razão seja capaz de dar conta do real e limita o campo do conhecimento ao fenomênico, ao aparente, ao não contraditónio.

7 KANT, Immanuel. Op. cit., p. 23.

KANT, Immanuel. Op. cit., p. 23.

KANT, Immanuel. Op. cit., p. 22. 


\section{2 - A ontologização da lógica em Hegel como meta-crítica \\ à crítica kantiana à ontologia clássica}

Hegel pretende superar a ontologia clássica e a filosofia critica. Segundo Manfredo Oliveira

"A conexão entre metafisica, filosofia transcendental e lógica especulativa é pensada por Hegel, como um processo de superação progressiva: Kant transformou a metafisica (sob a forma de ontologia geral no sistema de Wolff) em lógica transcendental; Hegel supera ambas em sua lógica especulativa". ".

Para Hegel, a metafísica considera as determinações do pensar como determinações das coisas, ou seja, ela parte do pressuposto de que o pensamento é capaz de dar conta do real. Neste sentido, as determinações do pensar eram tomadas como válidas e consideradas capazes de predicar o real, o verdadeiro. As$\operatorname{sim}$

"A Metafisica pressupõe que o conhecimento do absoluto podia ter lugar mediante o atribuir-lhe predicados e não indagava nem as determinações do entendimento segundo o seu peculiar conteúdo e valor, nem também a forma de determinar o absoluto pela atribuição de predicados".

Ora, na predicação somente interessava saber se o predicado (conceito) era ou não adequado ao sujeito pressuposto, de modo que seria considerado verdadeiro o predicado que não entrasse em contradição com o sujeito, portanto, o predicado era pensado analiticamente, por identidade, sem contradição.

Hegel critica a metafísica na sua forma de entender a predicação, portanto, na sua forma de determinar o real, excluindo a contradição. $O$ mesmo afirma que "se, pois, a verdade nada mais fosse que a carência de contradição, deveria primeiramente considerar-se, em cada conceito, se ele não conterá, para si, uma tal contrađição interna". "Ora, o princípio de contradição, que servia de sustentáculo para a metafísica, se expressa a nivel do conhecimento através do princípio do terceiro excluído, que formula a carência de contradição para a forma do juizo, logo, da predicação, do conhecimento.

Em relação a isso, Hegel afirma o seguinte: "A metafísica tornou-se dogmatismo, porque, segundo a natureza das determinaçöes finitas, teve de assumir que, de duas afirmações opostas, como eram essas proposiçōes, uma devia ser verdadeira, e a outra falsa". "Para Hegel, portanto, a metafísica partia de um ponto de vista especulativo, na medida em que considerava as determinações do pensar como determinações das coisas, entretanto, ela foi incapaz de pensar o real adequadamente, por excluir a contradição do real e da forma da predicação (o pensar).

Hegel também critica a lógica transcendental de Kant ou filosofia crítica. Ora, a filosofia crítica considera a experiência como o único campo de conhecimentos e se a percepção sensivel não nos dá a universalidade e a necessidade, esta provém

\footnotetext{
OLIVEIRA, Manfredo. Op. cit., (KANT - Cadernos UNB).

HEGEL, G. W. F. Enciclopédia das Ciências Filosóficas. p. 96-97.

HEGEL, G. W. F. Op. cit., p. 19.

HEGEL, G. W. F. Op. cit., p. 98.
} 
de espontaneidade do pensar, ou seja, a priori. Deste modo, então, os conceitos do entendimento constituem a objetividade dos conhecimentos de experiência.

É, portanto, tarefa da filosofia crítica examinar os conceitos do entendimento utilizado na metafísica e nas outras ciências. Para Hegel, a filosofia crítica não realizou esta tarefa, pois “[...] não entra no conteúdo e na relação determinada que as determinações do pensar entre si têm, mas considera-os em geral segundo a oposição de subjetividade e objetividade". ".

Kant alarga a tal ponto esta oposição de subjetividade e objetividade, que na subjetividade se apreende o fenômeno e do outro lado, nada resta a näo ser a "coisa em si", o real como ele é. As categorias são, portanto, consideradas subjetivas e vazias, devendo adquirir conteúdo mediante intuições sensiveis, e são ao mesmo tempo incapazes para determinar o real, logo, o entendimento é incapaz de conhecer o real em si, mas somente o fenômeno.

Para Manfredo Oliveira, "Hegel questiona esta contraposição entre subjetividade e objetividade e pretende pensar as categorias como adequadas, isto é, como expressão da identidade entre sujeito e objeto, que ele considera o princípio da especulação". Para Kant, entretanto, não podemos conhecer o real em si, mesmo tendo uma faculdade chamada razão, que tenta ultrapassar os limites do entendimento, da experiência. Para Kant, a razão quer pensar o real em si, mas ao conhecimento por ela formulado nada the corresponde objetivamente.

Há, portanto, no pensamento kantiano um dualismo entre pensamento e real, sujeito e objeto. Ora, para Hegel, se o pensamento e o real não se ajustam adequadamente, podemos considerar um ou outro deficiente. Pois bem, no idealismo de Kant a deficiência se desloca para os pensamentos e a contradição não existe no objeto, mas na razão cognoscente, nas categorias do pensar.

Ora, para Hegel, se a razão é assim reduzida a uma identidade vazia, ela se liberta da contradição mediante a perda de todo conteúdo e valor. $\mathrm{E}$ a isto ele se contrapõe, pois:

"O pensamento de que a contradição, posto no racional pelas determinaçōes do entendimento, é essencial e necessária, deve considerar-se como um dos mais importantes e mais profundos progressos da filosofia da era moderna".

Podemos perceber, portanto, que a lógica formal clássica e a lógica transcendental de Kant excluíram a contradição. Para Kant, é esta contradição existente na razão que a impede de formular um conceito adequado do real; o pensamento neste caso se restringe ao campo do fenômeno, não podendo realizar a grande pretensão do pensamento, da ciência, que é ser capaz de pensar o real como ele realmente é.

Hegel pretende superar esta concepção dualista das lógicas anteriores. Como ilustração disso, Roger Garaudy cita a introdução da ciência da Lógica de Hegel onde este afirma o seguinte:

* HEGEL, G. W. F. Op. cit., p. 103.

\% OLIVEIRA, Manfredo. Op. cit., (Kant - Cademos UNB).

Hegel, G. W. F. Op. cit. 
"O conceito de Lógica em vigor até aqui apóia-se na separação feita, de uma vez por todas, pela consciência ordinária, entre a verdade e a certeza. Supỏe-se, de um lado, que a matéria do conhecimento existe como um mundo inteiramente acabado, fora do pensamento, que este é vazio em si, que vem, enquanto forma, a se aplicar exteriormente a esta matéria, preencher-se, e somente assim adquirir um conteúdo e um conhecimento real".

Ora, além de pretender superar esta concepção dualista do pensamento ocidental, Hegel pretende pensar o real como processo, como automovimento. $\mathrm{Na}$ compreensão de Marcelo Aquino, "o programa filosófico de Hegel pode ser condensado na sua afirmação: "tudo depende de entender e compreender o verdadeiro. Não como uma substância, mas decididamente como sujeito" e para Paulo Menezes, "quem diz substância diz ser, que é o objeto imediato para um saber, também imediato, de um universal. Uma dupla imediatez, portanto". . Assim, então, o ser que é sujeito é negatividade, cisão que dilacera a imediatez, desdobrando-se para tornar-se concreto, de modo que todo conteúdo é reflexão sobre si mesmo e o saber não pode refletir em si fora dele, pois o que leva a ciência a organizar-se é o próprio movimento do conteúdo, que é um movimento dialético.

Hegel pretende, então, resgatar a ontologia através da ontologização da lógica. Não a ontologia clássica que para ele foi incapaz de pensar adequadamente o real, devido à exclusão da contradição do reino do pensar e do real. Ora, para Hegel mesmo a crítica feita à ontologia clássica pelo criticismo kantiano não se sustenta, pois na filosofia transcendental o pensar exclui a contradição.

Nesta perspectiva, a ontologia que Hegel quer resgatar é uma ontologia na qual há identidade de sujeito e objeto, pensar e ser e em que ambos são movimento e isto ele o faz, repensando a lógica, ou seja, ontologizando a lógica, pois a lógica hegeliana não só tem como ponto de partida a identidade entre pensamento e ser, mas também é concebida como um movimento de autodeterminação do "real racional ou racional real", que tem como motor de seu movimento a contradição.

\section{4 - Conclusão}

A relação entre pensar e ser é uma questão central da ciência, questão esta que vem sendo tematizada desde a antigüidade até a contemporaneidade. Como já vimos anteriormente, a filosofia surgiu no ocidente como uma pergunta pelo ser, pelo real enquanto totalidade.

É tese fundamental do pensamento clássico a convicção de que através da razão, do pensar, o homem pode conhecer o ser, dizer a natureza do real. Este ser, o real, é então concebido como o ser da concepção parmenídica, ou seja, o ser universal, imaterial e imutável, além das aparências sensíveis. Deste modo, a natureza do real está para além do sensível, além da experiência, sendo este o ser abstrato da razão abstrata, a qual para alcançar 'o real', abstraía o conteúdo sensivel deste, buscando o universal, o não sensível, considerando-o o ser enquanto tal.

\footnotetext{
* Garaudy, Roger. Para Conhecer o Pensamento de Hegel.

15 AQUINO, Marcelo. O Conceito de Religiäo de Hegel. p. 37.

` MENEZES, Paulo. Para Ler a Fenomenologia do Espírito. p. 15.
} 
Durante mais de dois mil anos de filosofia, o que se compreendeu como ciência, na sua acepção mais fundamental, foi a ontologia clássica. Pois bem, a ontologia clássica ou metafísica clássica adotou a tese de Parmênides e com ela formulou toda uma concepção do pensar, do real, da ciência; como já explicitamos anteriormente, foi Aristóteles quem sistematizou os principios fundamentais desta concepção do pensar, do real, e nesta sistematização, tanto o ser como o pensar carecem de contradição.

Ora, o ser carente de contradição é o ser que exclui de sua essência a mutabilidade, o sensível, sendo então o real visto, em sua essencialidade, como o ser substancial, imaterial, e imutável. De forma semelhante, o pensar carente de contradição é o pensar formal, que abstraía o conteúdo do pensar, de modo que só lhe resta a forma abstrata do pensar, a qual conduz a uma concepção formal da predicação e, portanto, do conhecimento do real.

Kant se incumbiu da tarefa de realizar a crítica e a negação da ontologia clássica. Partindo de uma nova concepção de saber, uma nova concepção de ciência, a qual afirma que o conhecimento só se faz através de conceitos a priori mediados pela experiência sensivel, ele se propõe a realizar tal tarefa.

Ora, se o conhecimento só se faz mediante a experiência (que na concepção kantiana se constitui através da sensibilidade, a qual mediante intuições sensiveis nos fornece o conteúdo do conhecimento, e do entendimento, que nos fornece conceitos a priori ou as regras pelas quais julgamos tal conteúdo), então, todo o nosso conhecimento é um julgar sensivel, portanto, todo ele se limita ao campo do sensivel, do fenômeno.

Com esta concepção do saber, Kant nega a possibilidade da metafísica clássica como ciência, pois ela queria conhecer mediante conceitos, abstraindo o sensível, a experiência, o que para Kant não corresponde a um saber cientifico. Ademais, Kant nega também que possamos fazer uma ontologia, pois querer conhecer a coisa em si, o nômeno, é querer ultrapassar os limites do entendimento e da ciência, a qual não pode ir além do fenômeno, da aparência.

Kant, porém, admite que a razão é uma faculdade que procura ultrapassar os limites do entendimento e, portanto, do conhecimento científico, entretanto, ele lhe nega tal possibilidade, pois quando o pensar racional quer ultrapassar o fenômeno e pensar o real como ele é, cai em contradiçōes insolúveis. Assim, portanto, Kant ao excluir da razão o pensar movido pela contradição, nega que possamos conhecer o real, nega a possibilidade da ciência ser uma ontologia e limita o saber ao campo do mundo dos fenômenos, ao campo das aparências.

Hegel, porém, pretende resgatar a ontologia, entretanto, não a ontologia clássica, que a partir da crítica kantiana tornou-se inconcebível enquanto ciência. $\mathrm{Na}$ compreensão de Hegel, é fundamental que a filosofia se aproxime da forma da ciência, ou seja, que ela deixe de ser amor ao saber e passe a ser saber efetivo. Ora, isto significa dizer que a ciência se constitui ciência ao se capacitar a expressar o real como ele realmente é, de modo que as categorias lógicas, que são o elemento em que se move o saber, não pode ser abstrata e carecer de conteúdo, sendo, portanto, uma lógica que é uma ontologia, ou seja, uma ciência que dá conta do real como ele realmente é. 
Para Hegel, o pensamento clássico partia de um ponto de vista especulativo, pois partia do pressuposição de que as determinações do pensar são determinações das coisas, de modo que a razão é capaz de conhecer o real como ele é. Entretanto, para ele, o pensamento clássico não foi capaz de realizar adequadamente a ciência enquanto ontologia, saber efetivo, e isto, por ter excluído do pensar e do ser a contrađição; quanto a Kant, por ter excluído a contradição não do real, mas do processo do pensar científico, impossibilitou à ciência o acesso ao real.

Nesta perspectiva, o ponto de partida do pensamento de Hegel, considerado por ele como o princípio da especulação, é a identidade de ser e pensar, do real e do racional, do lógico e do ontológico, que é uma condição indispensável para o resgate da ciência enquanto saber efetivo, enquanto ontologia; entretanto, esta identidade de ser e pensar não é a do pensamento clássico, que acreditava, por identidade abstrata, serem as determinações do pensar determinações das coisas, ou seja, que na identidade de pensar e ser excluía a contradição, portanto, o processo, o movimento, a negação, etc.

Com estes fundamentos, Hegel pretende realizar a ciência como saber efetivo, como ontologia. Porém, não a ontologia da substância imóvel, pensada por identidade abstrata, carente de contradição, mas a ontologia do ser como sujeito, como movimento que se autodetermina, portanto, do ser que se realiza através da contradição, do processo.

Podemos concluir, portanto, que para Hegel a ciência se faz ciência como ontologia e o saber só será efetivo e terá a forma da ciência, enquanto for ontológico. Neste horizonte, o real é racional e o racional é real, e mais, se o pensamento anterior a Hegel não foi capaz de realizar uma ontologia adequada, científica, efetiva, e até mesmo negou a própria ontologia, devido ao fato de excluir do real e/ou do pensamento a contradição, então, a categoria de contradição é uma categoria fundamental para a ontologização da lógica em Hegel e, portanto, para o resgate da ontologia enquanto ciência.

\section{Referências bibliográficas}

AQUINO, M. F. O Conceito de Religião em Hegel. São Paulo, Ediçōes Loyola. ARTSTÓTELES. A Metafisica. Porto Alegre, Editora Globo. HEGEL, G. W. F. Enciciopédia das Ciências Filosóficas em Epítome. Lisboa, Edições 70.

- A Fenomenologia do Espíito (em Hegel, Os pensadores). São Paulo, Abril Cultural.

- Ciencia de la Logica. Buenos Aires, Librarie Hachette S/A.

KANT, Immanuel. Crítica da Razão Pura. Lisboa, Fundação Calouste Gulbenkian. MENEZES, Paulo. Para Ler a Fenomenologia do Espírito. São Paulo, Edições Loyola. OLIVEIRA, Manfredo. Lógica Transcendental e Lógica Especulativa (em Kant, Immanuel, cadernos UNB.).

ROSS, David. Aristóteles. Lisboa, Dom Quixote. 